\title{
BMJ Open WHO guidance on mental health training: a systematic review of the progress for non-specialist health workers
}

\author{
Alexandra Caulfield, ${ }^{1,2}$ Deniz Vatansever, ${ }^{3,4}$ Gabriel Lambert, ${ }^{1}$ Tine Van Bortel ${ }^{5,6}$
}

To cite: Caulfield $A$,

Vatansever D, Lambert $\mathrm{G}$, et al. WHO guidance on mental health training: a systematic review of the progress for non-specialist health workers. BMJ Open 2019:9:e024059. doi:10.1136/ bmjopen-2018-024059

- Prepublication history and additional material for this paper are available online. To view these files, please visit the journal online (http://dx.doi. org/10.1136/bmjopen-2018024059).

$\mathrm{AC}$ and $\mathrm{DV}$ contributed equally.

Received 12 May 2018

Revised 30 0ctober 2018

Accepted 14 November 2018

Check for updates

(C) Author(s) (or their employer(s)) 2019. Re-use permitted under CC BY-NC. No commercial re-use. See rights and permissions. Published by BMJ.

${ }^{1}$ Department of Medicine, School of Clinical Medicine, University of Cambridge, Cambridge, UK ${ }^{2}$ Department of Public Health Sciences, Karolinska Institutet, Stockholm, Sweden

${ }^{3}$ Department of Psychiatry, University of Cambridge, Cambridge, UK

${ }^{4}$ Department of Psychology, University of York, York, UK ${ }^{5}$ Cambridge Institute of Public Health, University of Cambridge, Cambridge, UK

${ }^{6}$ Institute for Health and Human Development, University of East London, London, UK

Correspondence to

Dr Tine Van Bortel;

tv250@medschl.cam.ac.uk

\section{ABSTRACT}

Objective To assess existing literature on the effectiveness of mental health training courses for nonspecialist health workers, based on the WHO guidelines (2008).

Design A systematic review was carried out, complying with the Preferred Reporting Items for Systematic Reviews and Meta-Analyses checklist.

Data sources After examination of key studies in the literature, a comprehensive search was performed within the following electronic databases on 31 May 2017: PubMed, PsycINFO, CINAHL (using EBSCOHost interface), Cochrane, Web of Science.

Eligibility criteria Searches were conducted for articles published in English from January 2008 to May 2017, using search terms related to mental health, training, community care and evaluation/outcome, following the Participants, Interventions, Comparators and Outcomes process for evidence-based practice.

Outcomes Data were collected across the following categories: trainees (number and background), training course (curriculum, teaching method, length), evaluation method (timing of evaluation, collection method and measures assessed) and evaluation outcome (any improvement recorded from baseline). In addition, studies were assessed for their methodological quality using the framework established by Liu et al (2016).

Results 29 studies with relevant training courses met the inclusion criteria. These were implemented across 16 countries since 2008 (over half between 2014 and 2017), with 10 in three high-income countries. Evaluation methods and outcomes showed high variability across studies, with courses assessing trainees' attitude, knowledge, clinical practice, skills, confidence, satisfaction and/or patient outcome. All 29 studies found some improvement after training in at least one area, and 10 studies found this improvement to be significant. Conclusions Training non-specialist workers in mental healthcare is an effective strategy to increase global provision and capacity, and improves knowledge, attitude, skill and confidence among health workers, as well as clinical practice and patient outcome. Areas for future focus include the development of standardised evaluation methods and outcomes to allow cross-comparison between studies, and optimisation of course structure. PROSPERO registration number CRD42016033269

\section{Strengths and limitations of this study}

- This review evaluated the existing literature on the effectiveness of short mental health training courses with the aim of informing future policy-making.

- The Participants, Interventions, Comparators and Outcomes process for evidence-based practice was followed to perform a wide search across five electronic databases and extract data in a wide range of categories.

- Studies were assessed for methodological quality using a standardised outcome framework, and accuracy was ensured through multiple quality assurance processes, including independent data extraction by reviewers, and additional random sampling.

- This review only included studies which provided an evaluation of training; other 'unevaluated' courses might have contributed to a broader 'global' uptake.

- This review covered 'general mental health' and did not include studies which evaluated training targeted for specific subpopulations (eg, refugees), for single conditions (eg, depression only), for medical students or specialists (ie, non-generalist practitioners).

\section{INTRODUCTION}

Mental ill-health is a leading cause of disability worldwide, ${ }^{1}$ accounting for more than $13 \%$ of the global burden of disease. ${ }^{2}$ Responsible for $33 \%$ of total years lived with disability, ${ }^{3}$ mental health problems are projected to affect at least one in three people over their lifetime. ${ }^{4}$ Furthermore, it is estimated that people with severe mental illness (eg, schizophrenia, bipolar disorder and severe depression) are $60 \%$ more likely to die prematurely than those unaffected. ${ }^{5}$ Such high prevalence also has major economic consequences. It is estimated that mental ill-health will cost the global economy $\$ 16.3$ trillion between 2011 and $2030^{6}$ which has serious implications for socioeconomic development and standards of living. Despite this global picture, stigma, governmental apathy and other barriers 
to treatment persist, exacerbating the current state of mental healthcare worldwide. ${ }^{78}$

Aiming to address these concerns, an influential Lancet series published in $2007,{ }^{9}$ with follow-up series in $2011,{ }^{10}$ marked the beginning of an era that recognises the importance of mental health in global health policy. Expanding on this, the WHO issued a comprehensive report in 2008 on the current state of mental health provisions globally. ${ }^{11}$ In response to its clinical, epidemiological and health economic findings, United Nations policy recommended a transition from tertiary, institutionalised mental healthcare towards the integration of mental health services into primary care with community support. This was projected to improve health outcomes, cost-effectiveness, access to services and reduce human rights abuses and stigma.

To help countries achieve this, WHO identified ten key principles for mental healthcare integration, drawn from best practice examples worldwide. ${ }^{11}$ One of these points recommended adequate training of primary care workers in diagnosing and treating mental ill-health, laid out in the WHO Mental Health Action Plan (2013-2020) ${ }^{5}$ and the WHO Mental Health Gap Action Programme (mhGAP) ${ }^{12}$ Such training is crucial to increase capacity for mental healthcare delivery across countries, particularly those with small or previously non-existent budgets for mental health. However, the effectiveness of such provisions in treating mental health disorders has not been systematically assessed.

Therefore, the purpose of this systematic review was to examine the global response to 2008 WHO policy on mental health training of non-specialist health workers. By identifying all published reports on evaluations of training that took place following WHO guidance, we aimed to systematically assess whether countries have responded to WHO's call for action, identify how such courses were run and evaluated, and identify patterns of good practice and outcomes of this training. The results of our analysis enabled us to develop recommendations for future courses, as well as to improve outcome and evaluation methods.

\section{DATA COLLECTION}

\section{Search strategy}

This systematic review was completed and reported according to the Preferred Reporting Items for Systematic Reviews and Meta-Analyses (PRISMA) guidelines. ${ }^{13}$ As this was an evidence synthesis of existing research, ethical approval was not required; however, we fully complied with the Declaration of Helsinki on medical research.

Aiming to identify publications on mental health training for non-specialist groups worldwide, we searched for terms related to mental health, training, community and evaluation in the following electronic databases on 31 May 2017: PubMed, PsycINFO, CINAHL (using EBSCOHost interface), Cochrane and Web of Science. We included controlled vocabulary terms for each database
Table 1 Systematic review search strategy following the Participants, Interventions, Comparators and Outcomes process for evidence-based practice

\begin{tabular}{|c|c|c|c|}
\hline Participants & Intervention & & Outcome \\
\hline $\begin{array}{l}\text { Mental } \\
\text { health }\end{array}$ & $\begin{array}{l}\text { Train* } \\
\text { (train, training) }\end{array}$ & Primary care & $\begin{array}{l}\text { Evaluat* }^{*} \text { (evaluate, } \\
\text { evaluation, } \\
\text { evaluating) }\end{array}$ \\
\hline $\begin{array}{l}\text { Mental } \\
\text { illness }\end{array}$ & $\begin{array}{l}\text { Educat }^{*} \\
\text { (educate, } \\
\text { education, } \\
\text { educating) }\end{array}$ & $\begin{array}{l}\text { Primary } \\
\text { healthcare }\end{array}$ & Outcome \\
\hline \multirow[t]{8}{*}{$\begin{array}{l}\text { Mental } \\
\text { disorder }\end{array}$} & $\begin{array}{l}\text { Program } \\
\text { (programme) }\end{array}$ & $\begin{array}{l}\text { Primary } \\
\text { health care }\end{array}$ & $\begin{array}{l}\text { Detect }^{\star} \\
\text { (detect, } \\
\text { detection, } \\
\text { detecting) }\end{array}$ \\
\hline & $\begin{array}{l}\text { Toolkit } \\
\text { (tool kit) }\end{array}$ & $\begin{array}{l}\text { Community } \\
\text { care }\end{array}$ & $\begin{array}{l}\text { Diagnos* } \\
\text { (diagnose, } \\
\text { diagnosis, } \\
\text { diagnosing) }\end{array}$ \\
\hline & & $\begin{array}{l}\text { Community } \\
\text { healthcare }\end{array}$ & $\begin{array}{l}\text { Measur* } \\
\text { (measure, } \\
\text { measurement, } \\
\text { measuring) }\end{array}$ \\
\hline & & $\begin{array}{l}\text { Community } \\
\text { health care }\end{array}$ & Attitude \\
\hline & & Integration & Stigma \\
\hline & & $\begin{array}{l}\text { Integrated } \\
\text { care }\end{array}$ & \\
\hline & & $\begin{array}{l}\text { Integrated } \\
\text { healthcare }\end{array}$ & \\
\hline & & $\begin{array}{l}\text { Integrated } \\
\text { health care }\end{array}$ & \\
\hline
\end{tabular}

and searched for articles published from January 2008 to May 2017 (inclusive). The search strategy (table 1) was designed after careful examination of key studies in the literature, and by following the Participants, Interventions, Comparators and Outcomes (PICO) process for evidence-based practice. ${ }^{14}$ The full search strategy for the PubMed database is provided as an example in the online supplementary material.

We included studies reported in English, meeting the following criteria in line with the PICO design:

- Participants: Following WHO guidance for increasing mental healthcare capacity through task-shifting, ${ }^{12}$ we included studies in which trainees were non-specialist healthcare workers (eg, generalist medical practitioners, nurses, general community mental healthcare workers and non-medical volunteers). Studies focusing on specialists (eg, psychiatrists) and medical students were excluded as these groups may have received specialist training in addition to a short training course. In line with WHO guidance, we were interested in the efficacy of programmes that could be readily administered without extensive training. 
We therefore wanted to ensure that this potential confounding factor was removed from our search strategy.

- Intervention: Studies describing the training course format and outcome in general mental health were included. Duration or format were not used as selection criteria. We excluded studies providing training to care for specific subpopulations (eg, children, veterans and/or specific ethnic groups), for one specific mental illness (eg, depression alone) and those covering substance abuse (eg, alcoholism) or mental illnesses secondary to other medical conditions (eg, HIV/AIDS). A further search term, related to 'primary care', was instead used to identify courses that focused on integration of mental health into primary care in line with WHO guidelines.

- Comparison: Studies were not required to have a control comparison group, due to the exploratory nature of the review.

- Outcomes: We included studies that evaluated training course outcomes via quantitative or qualitative methods, or a combination of both. We excluded studies that did not provide any evaluation data.

References identified through the search strategy were uploaded into EndNote (X7, Thomson Reuters). After deduplication, titles and abstracts were independently double-screened following the eligibility criteria. Studies meeting the inclusion criteria were obtained as full text articles and independently double-screened by two reviewers using the same criteria. Entries that matched between the two reviewers were included. Unmatched entries were only included following resolution through discussion.

\section{Data extraction}

Standardised, piloted data extraction sheets were developed to ensure consistency between studies. Data were extracted by one reviewer and independently doublechecked by another. Additional quality control of a random sample was carried out by a third reviewer. Data extracted for each study included, where possible, primary care factors (country of origin, World Bank economic status, number and type of trainees), training factors (types of disorder included, method of training, duration and type of course and frequency of training) and outcome factors (outcomes measured, method and timing of evaluation). Any disagreements were resolved through discussion.

\section{Methodological assessment}

We followed the schema established by Liu et $a l^{15}$ for assessing methodological quality of mental health training courses in Africa, to allow wider comparisons within the field. This framework is based on a combination of validated methods, including the Newcastle-Ottawa Scale, ${ }^{16}$ Grading of Recommendations Assessment, Development and Evaluation ${ }^{17}$ and Methodological Index for Non-Randomised Studies. ${ }^{18}$ It examines the selection (five criteria) and evaluation methods (five criteria) in each study. Studies are given one point for each of the criteria they satisfy. Authors AC, GL and DV undertook this assessment and resolved any disagreements through discussion; TVB performed the quality control.

\section{Classification of training courses and outcomes}

Course trainees were categorised according to WHO classifications of healthcare workers. ${ }^{19}$ Since this only includes healthcare workers, we added three further categories, namely: volunteers, mental health consumers/carers and non-medical staff. The latter included police officers, farm inspection officers, disaster relief staff, educators and housing outreach workers. Studies identified and included these groups as first-line contacts for communities in distress or those which are difficult to reach.

In terms of content, courses were classified as 'specific' if they addressed one particular aspect of mental healthcare (eg, a specific management or counselling technique), and 'general' if they covered general psychiatry. A third category, 'emergency mental health', covered courses teaching mental health first aid and mental health in disaster settings. Additionally, we screened courses to identify if they had specifically used the mhGAP guide to create training modules.

Following Liu et $a l^{15}$ interventions were classified as 'didactic' when they were exclusively made up of lectures and as 'interactive' when they included active trainee participation such as role play, small-group work, case discussions or clinical skills. 'Mixed sessions' included both didactic and interactive elements. We also used the schema adapted from Kirkpatrick ${ }^{20}$ to classify types of evaluative outcome into one or more of seven areas: (a) satisfaction with training (evaluation of reaction), (b) change in attitude towards the importance of mental health, (c) change in confidence, (d) change in knowledge, (e) change in clinical skills (evaluation of learning), (f) change in clinical practice (evaluation of behaviour) and (g) change in patient outcomes (evaluation of results). ${ }^{21}$ For the purpose of this systematic review, we defined skill as the ability to perform a task well, usually gained by training or experience. ${ }^{22}$ We then reported how this skill was measured. We deliberately followed similar classification strategies to Liu et $a l^{15}$ to encourage establishment of a systematic method of review in this area, allowing cross-comparison between reviews.

\section{Patient and public involvement}

There was no patient or public involvement in this review, this was a synthesis of existing published data.

\section{Findings}

Our initial search identified 17877 results after deduplication $(n=3600)$. Screening of abstracts for PICO eligibility criteria resulted in inclusion of 47 papers from reviewer 1 and 64 papers from reviewer 2. Studies were discussed by reviewers to agree on validity of inclusion. Papers describing the same study were evaluated and excluded 


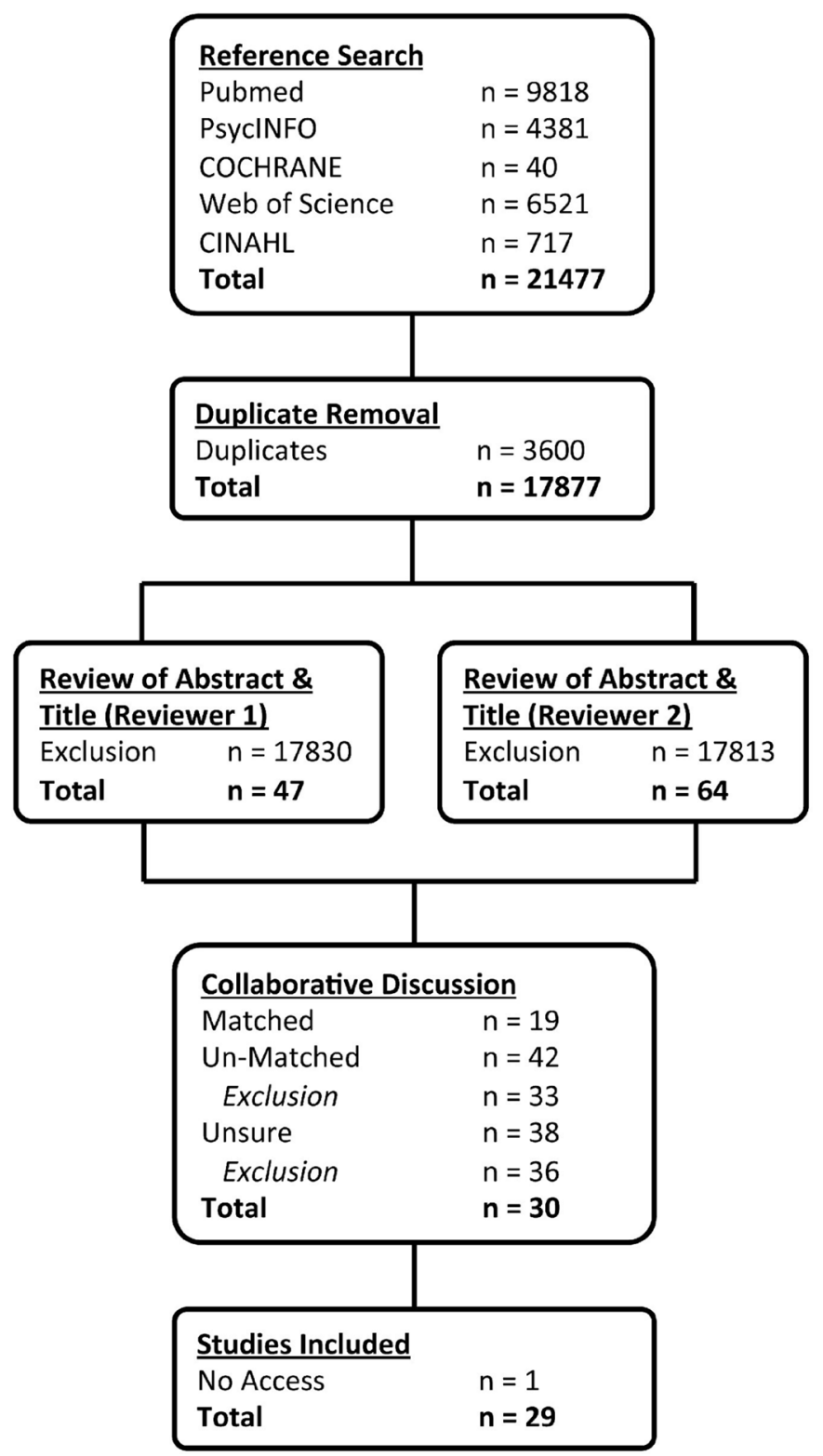

Figure 1 Preferred Reporting Items for Systematic Reviews and Meta-Analyses search strategy.

if they added no new information. A total of 30 studies were ultimately included, of which one was unobtainable. A random selection of papers was quality-controlled. Full PRISMA search strategy flow shown in figure 1.

\section{Country and economic status}

This systematic review identified that training interventions were implemented in 16 countries (figure 2): four in the UK, three each in Australia, Canada and India, two each in China, Malawi, Nigeria and Zimbabwe and one each in Iraq, Kenya, Nepal, Norway, Sierra Leone, Sri Lanka, USA and Pacific Small Island States. Countries were classified according to World Bank Economic Status (source: World Bank). Under this classification, six training courses took place in low-income settings, seven in lower-middle-income settings, two in upper-middle-income and 13 in high-income settings. Pacific Small Island
States was categorised as an 'aggregates' nation. International organisations were involved in the implementation of two of the courses: The Catholic Agency for Overseas Development provided medication and funded counsellors' salaries for the course in Sierra Leone, and the International Medical Corps appointed mental health advisors to oversee training in Iraq.

Studies were independently assessed by three reviewers using methodological criteria outlined by Liu et $a l^{15}$ (table 2). On comparison of findings, differences were resolved through discussion. Two areas proved challenging to assess; first, an agreed threshold for 'sufficient' detail for selection of the training sample, and second an agreed threshold for 'representative' selection of the evaluation sample. To clarify, the 'training sample' were the participants selected as trainees for each course, and the 'evaluation sample' consisted of the subgroup of trainees selected to participate in feedback/evaluation. In many cases, the evaluation samples were convenience samples, based on who was available and willing to provide feedback, rather than a representative group.

The median score of the studies in the methodological evaluation was five. A training sample of over 30 people was recruited in $22(76 \%)$ studies, while $17(59 \%)$ used a cohort that was representative of the target population. Selection of the training sample was adequately described in $17(59 \%)$ studies. Only six (21\%) trials used a control cohort, of which five used randomisations (four at clinic level and two by individual participants).

Selection of the evaluation sample was well characterised in $26(90 \%)$ studies, but only $19(66 \%)$ fully reported their evaluation and ensured evaluation samples were representative. Preintervention assessment was carried out in $19(66 \%)$ studies and only $13(45 \%)$ included long-term evaluation. The six studies that used a control cohort all used more detailed assessment tools than simple questionnaires, such as blinded reviewer scoring of competence of simulated patient consultations, rate of accurate clinic detection of mental disorders, data on diagnoses made by participants and direct observation of health worker skills. Therefore, the high-quality studies differentiated themselves through randomisation and moving beyond evaluation through the standard preintervention and postintervention questionnaire.

\section{Classification and number of trainees}

Community health workers were the most common type of trainee (table 3), featuring in more than half of interventions: $16(55 \%)$. A total of 10 courses $(34 \%)$ trained nurses, 7 (24\%) trained general medical practitioners, 7 (24\%) trained social workers and/or counsellors, $2(7 \%)$ trained health service managers and $1(3 \%)$ trained paramedics and clerical support workers. Seven courses $(24 \%)$ trained non-medical staff, two $(7 \%)$ trained volunteers and one $(3 \%)$ trained service users and carers. In 12 interventions $(41 \%)$, more than one type of trainee participated. Of these, five courses $(17 \%)$ trained two different types of participants, two $(7 \%)$ trained three 


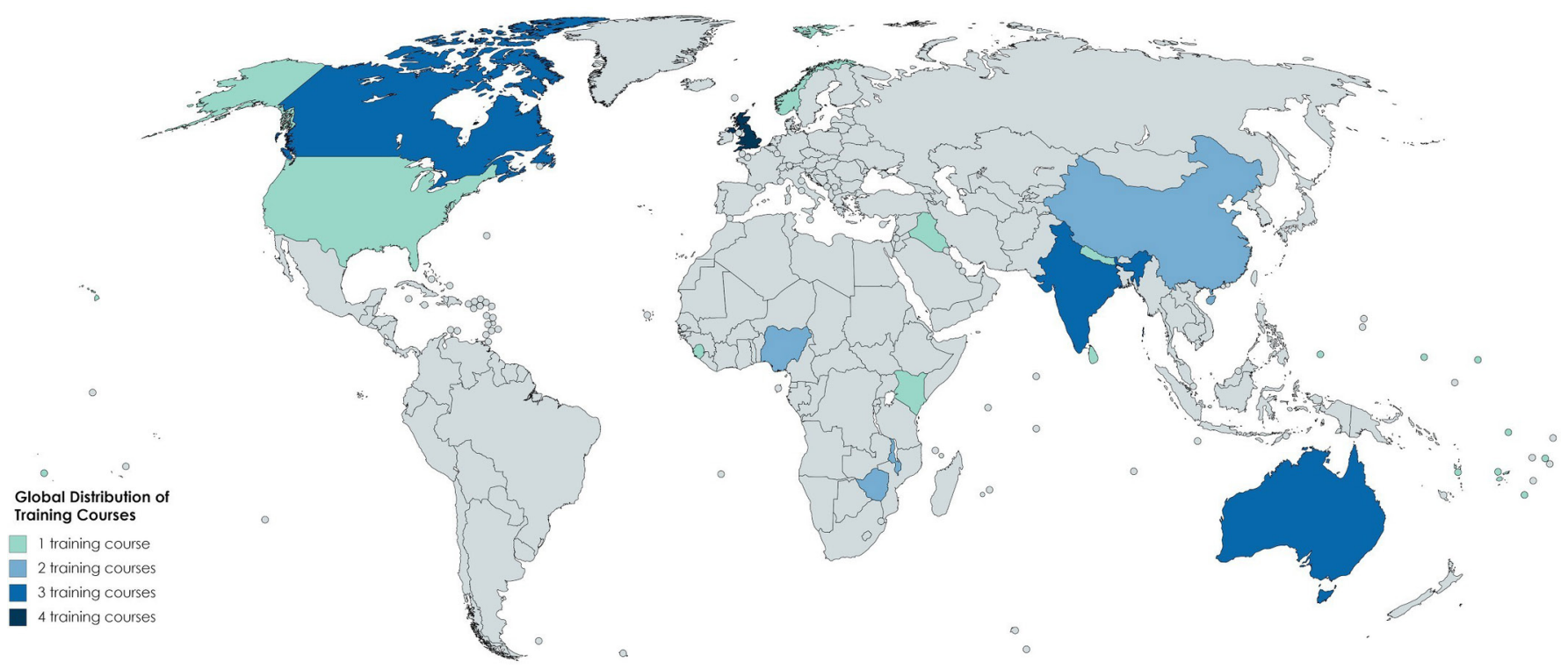

Figure 2 Global distribution of training courses for included studies.

types of participants, four (14\%) trained four types of participants and one $(3 \%)$ trained five types of participants. The latter course was particularly diverse, with trainees drawn from five different backgrounds, including physicians, nurses, social workers, paramedics and police officers. The number of trainees varied widely between interventions, ranging from just three to over 3500 .

\section{Course content}

Training course curricula varied (table 3): 15 courses $(52 \%)$ covered a 'general' curriculum, of which one also taught mental health first aid, one additionally addressed stigma and one included both. Of these general courses, two $(7 \%)$ followed the same 5-day curriculum, namely the Kenya Medical Training College mental health primary care training toolkit created in Kenya and subsequently adapted for other countries. Eleven courses (38\%) taught a 'specific' aspect of mental healthcare using a variety of previously established psychotherapies (eg, cognitive behavioural therapy), or focused on the development of teamwork skills via the New Ways of Working Framework, Access to Mental Health in Primary Care Programme, Rural Mental Health Inter-Professional Training Programme and Friendship Bench Programme. These teamwork development programmes were specifically created for the training interventions, most of which were tailored to the sociocultural background of the country in which they were implemented. Moreover, three courses $(10 \%)$ focused on emergency mental health, of which two taught mental health first aid and one taught mental health in natural disasters.

In terms of teaching methods, five courses $(17 \%)$ used didactic methods and six (21\%) used interactive methods, though the majority of courses (62\%) used a combination of methods providing an immersive learning experience. One course $(3 \%)$ also offered a choice of teaching methods, based on participants' favoured learning styles. In this case, trainees were more likely to drop out of self-directed learning than small group teaching. To provide access for remote trainees, two $(7 \%)$ courses used video-conferencing.

Course lengths varied ranging from 1 day to spread across 2 years. More than half the courses $(62 \%)$ ranged in length from 1 day to 2 weeks, and nine courses $(31 \%)$ lasted between 2 weeks and 2 years. Length of training could not be determined for two courses $(7 \%)$. Of the 29 courses identified by this study, $15(52 \%)$ ran training over a continuous period, and $13(45 \%)$ courses were sessional spread over a longer period. Course structure could not be determined for one course $(3 \%)$.

\section{Frequency of training}

Twelve studies $(41 \%)$ incorporated data from the same course run on multiple occasions in different localities (to improve access for trainees). The total numbers trained across these courses are listed in table 3. A further eight studies (28\%) reviewed courses which had already been evaluated elsewhere and then adapted to incorporate changes. It was difficult to determine total numbers trained over time for these courses. Of note, one study was a follow-up randomised clinical trial for the Friendship Bench Project in Zimbabwe, as recommended in an earlier evaluation of the same project.

\section{Evaluation methods}

The majority of courses (66\%) used a preintervention and postintervention design (table 3). Eleven courses $(38 \%)$ also collected evaluation data at later time-points postcourse to assess longer-term changes, four were (14\%) randomised controlled trials and one $(3 \%)$ was a controlled trial. A total of 10 courses (34\%) collected outcome measures after the intervention only. Of these, three $(10 \%)$ collected data at repeated time points postintervention and one (3\%) was a randomised controlled 


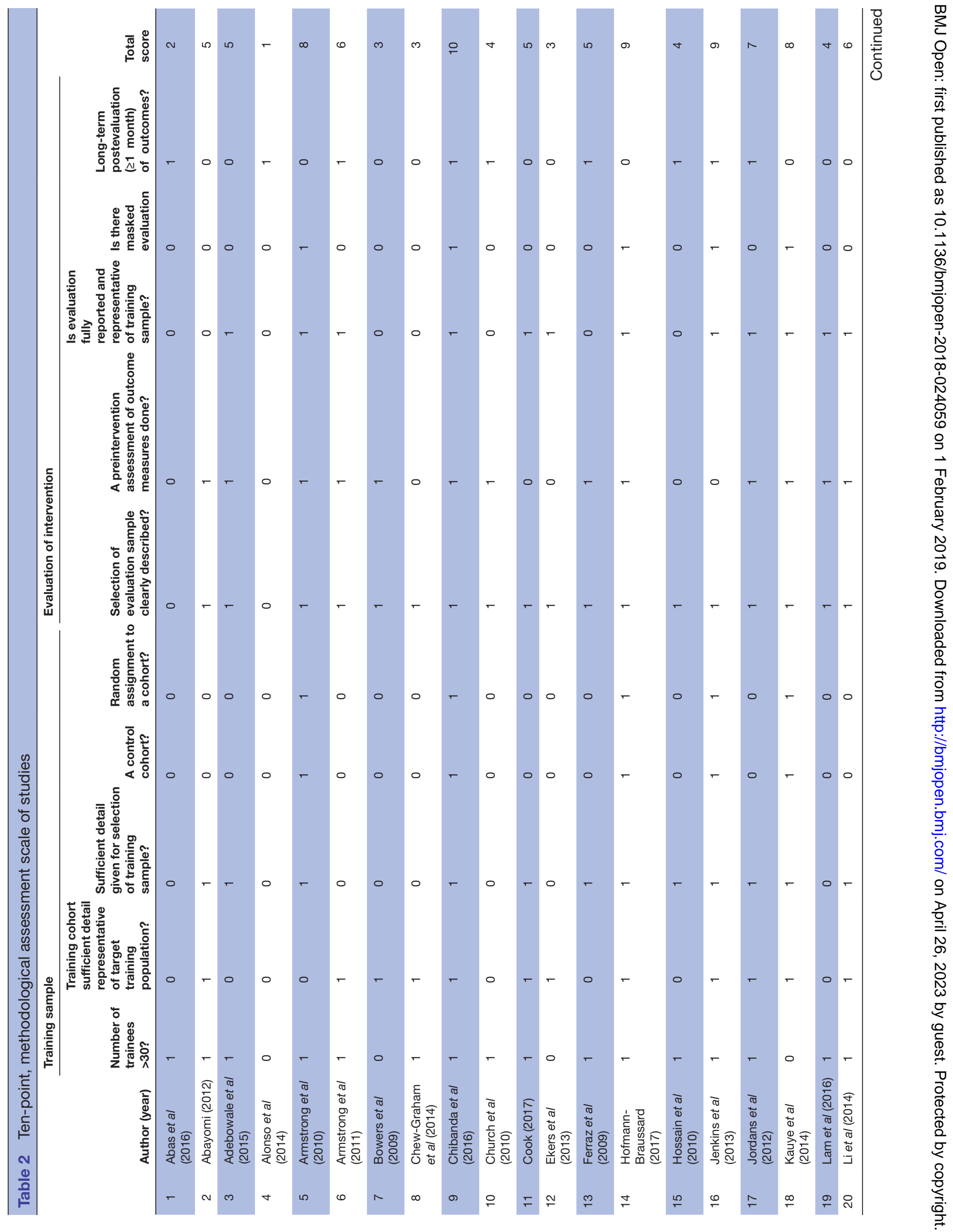




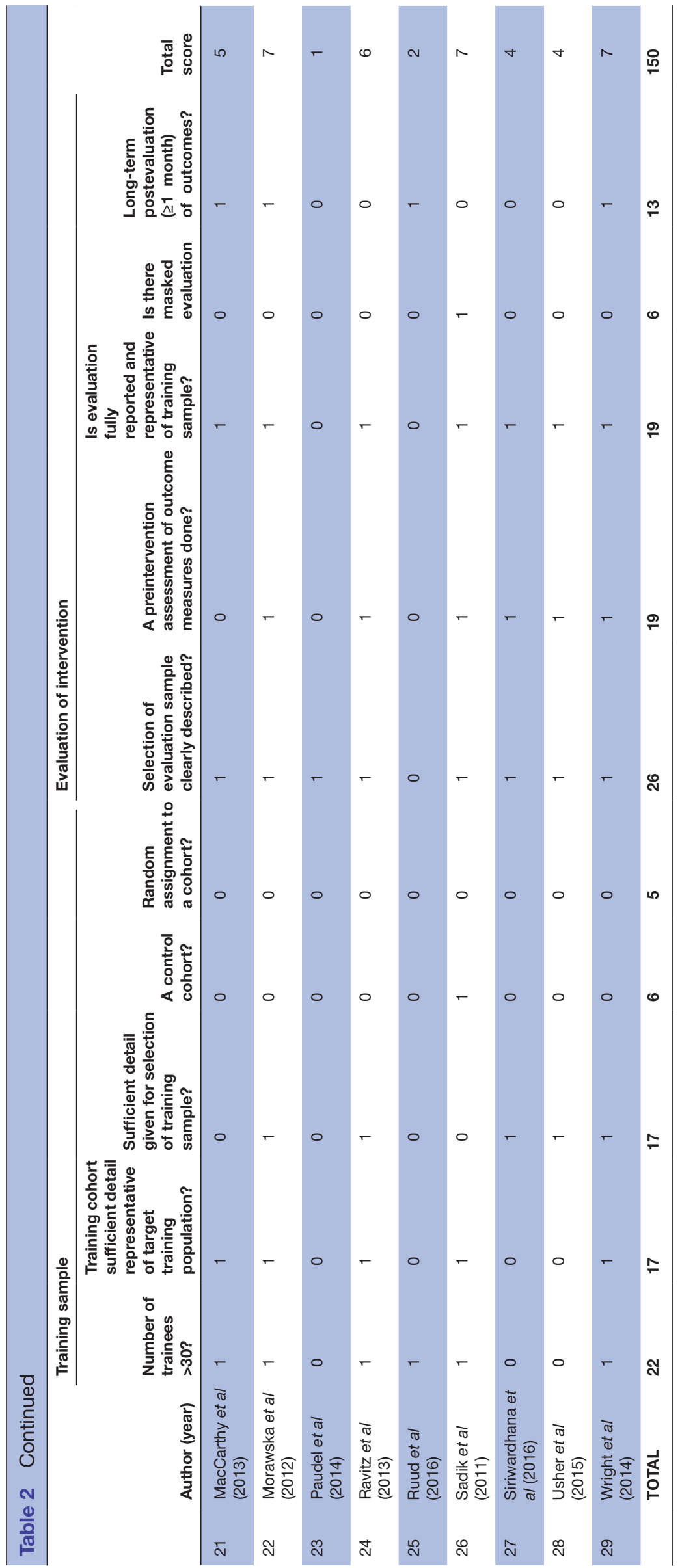

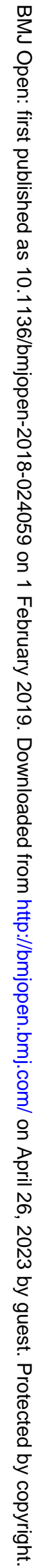




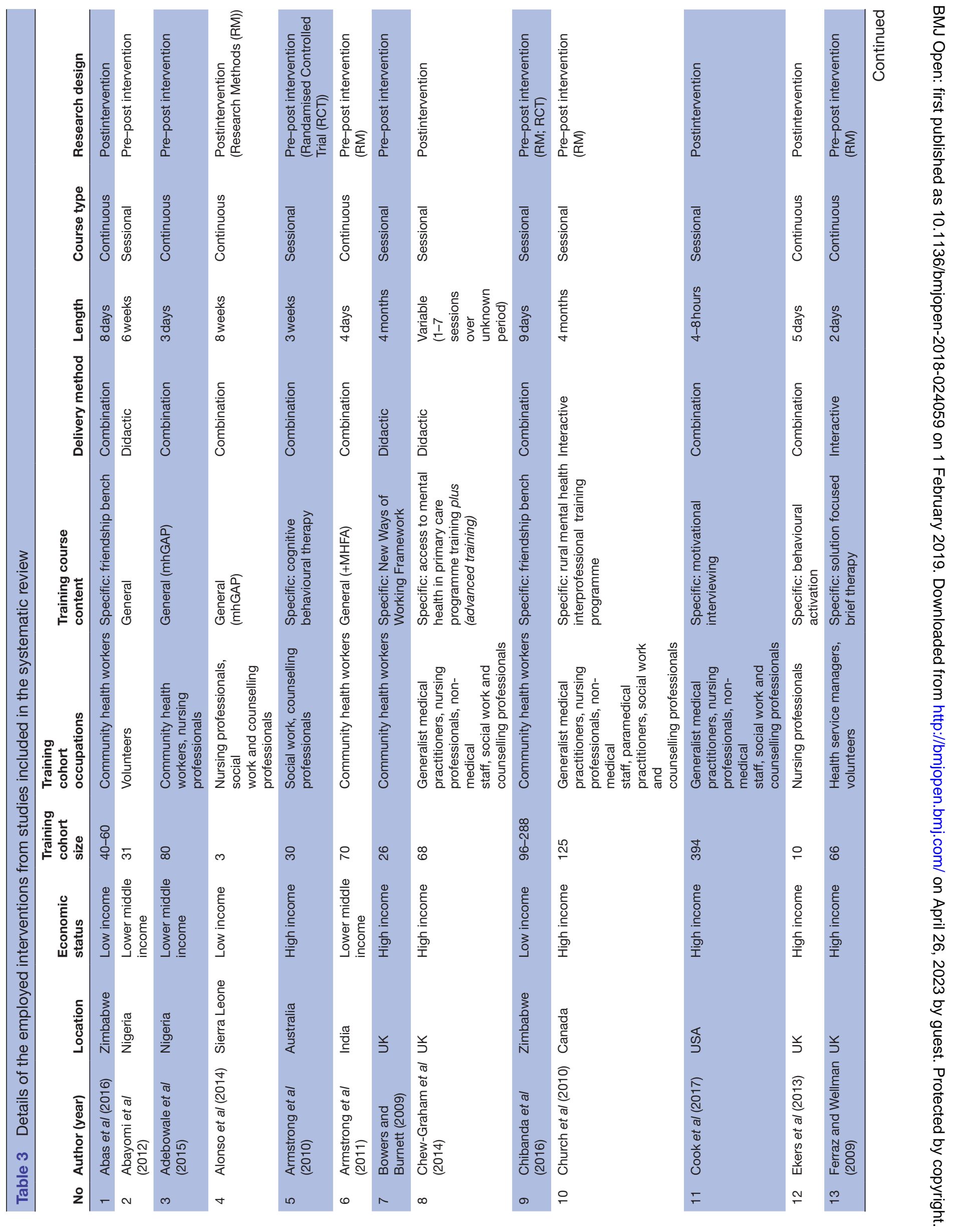




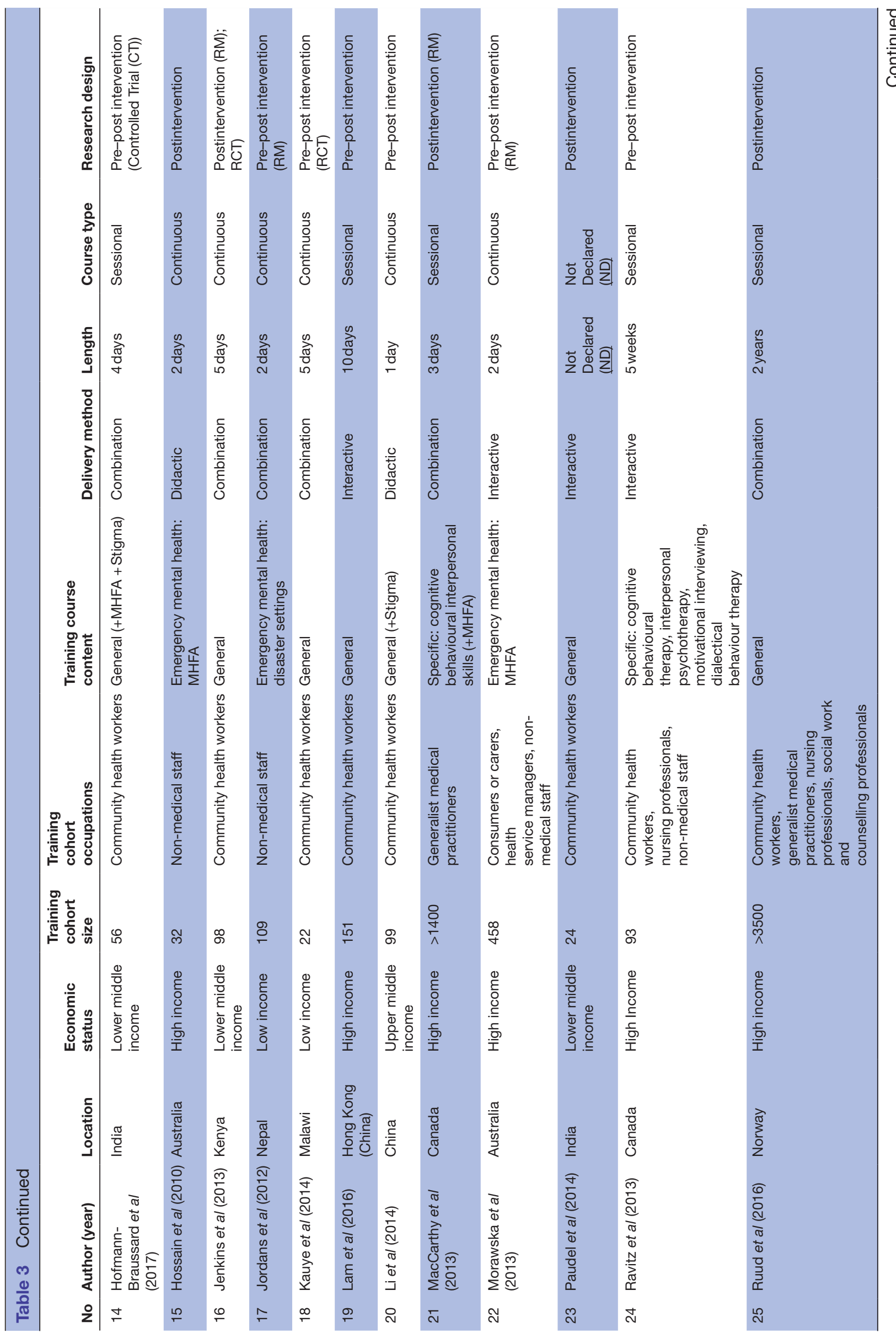


trial. One course $(3 \%)$ was designed for data collection while the course was ongoing, comprising written feedback gathered from participants at the end of each training session.

The type of data collected and tools used for data collection varied enormously across interventions. The majority of courses $(52 \%)$ collected quantitative data alone, while three courses $(10 \%)$ collected qualitative data alone, and 11 courses $(38 \%)$ collected both. The evaluation methods varied greatly with the majority of courses using written tools in the form of questionnaires or clinical vignettes. Further, focus groups or interviews with trainees were commonly used to establish the outcome of training courses. Some other courses examined case records or clinical notes of encounters to collect evaluation data, in several cases comparing clinical notes to patient status determined by previously validated screening tools, such as the General Health Questionnaire, Self-Rating Questionnaire and Structured Clinical Interview for Diagnostic and Statistical Manual of Mental Disorders (DSM-IV) for depression. In addition, a few courses used views of third parties as evaluation data (eg, course facilitator's field notes, or subjecting trainees to observation by blinded psychiatrists who watched simulated video-taped consultations or clinical encounters with real patients).

\section{Evaluation outcomes}

Course evaluation measures also varied (table 4). The most commonly measured outcome $(52 \%)$ was change in trainees' attitude towards mental health. Of these 15 courses, 13 found an improvement in attitude with six reporting significant improvements, five found a qualitative improvement and two found an absolute improvement from baseline. One course found no significant change in trainees' attitude preintervention and postintervention, and one course was an observational study testing significant difference in knowledge, attitude and clinical practice across trainee demographics, years of practice, practice setting and so on. The second most common outcome measured $(45 \%)$ was knowledge. Of these, 10 courses found an improvement in knowledge postintervention, with six reporting significant improvement and four an absolute improvement. One course measured postintervention knowledge only, reporting it as 'impressive', one course reported no significant improvement and one was the observational study reported above. Clinical practice and clinical skills were measured by 11 courses (38\%). Measurement of clinical practice was largely qualitative in nature, and suggested positive change in practice following training. Three courses $(10 \%)$ attempted to quantify change in clinical practice, of which two found a significant improvement and one found no change. Clinical skills were assessed by 11 courses $(38 \%)$. Of these, seven found a statistically significant improvement in clinical skills, two found a qualitative improvement, and two no improvement from baseline. Change in confidence was assessed by nine courses $(31 \%)$, with seven finding statistically significant 


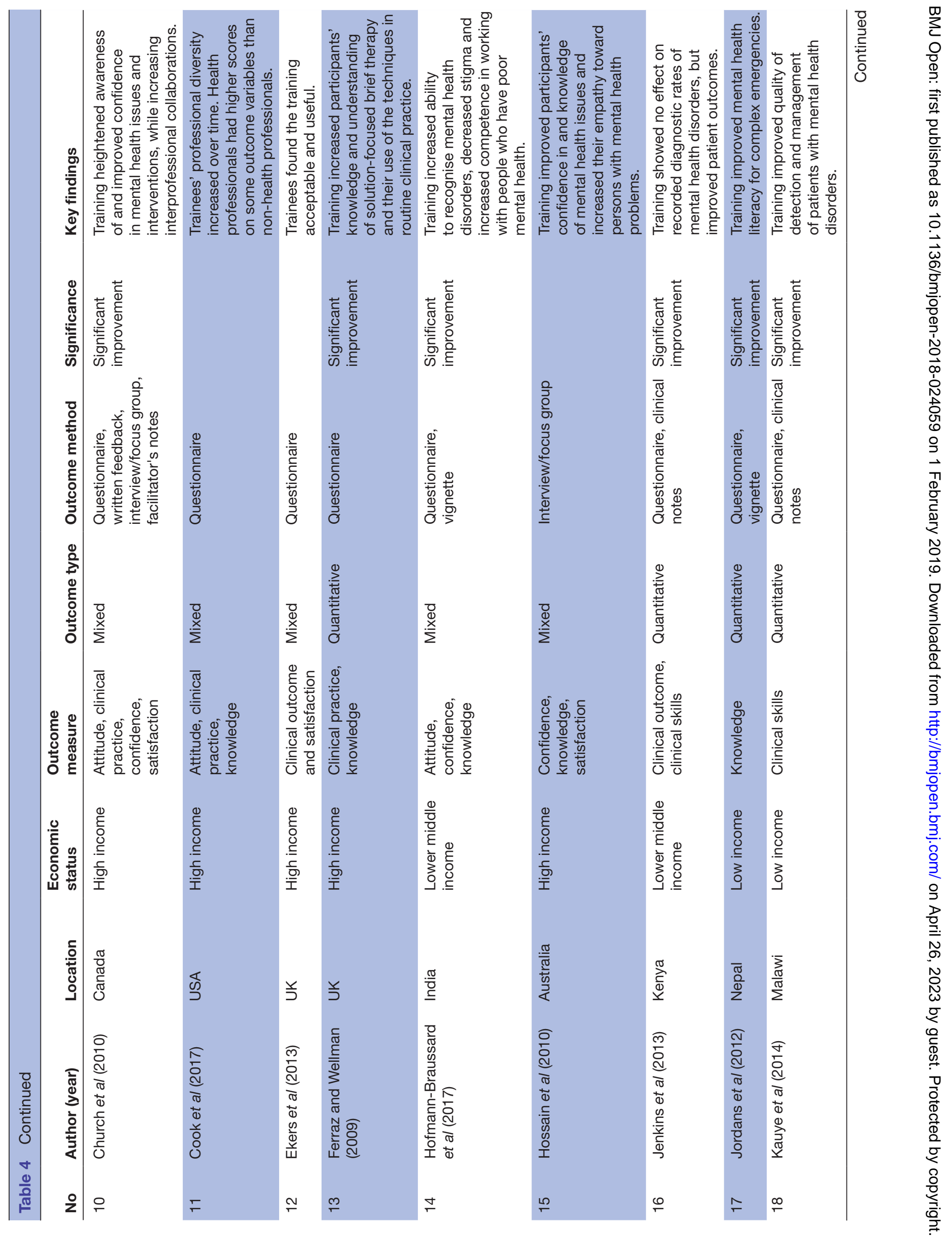




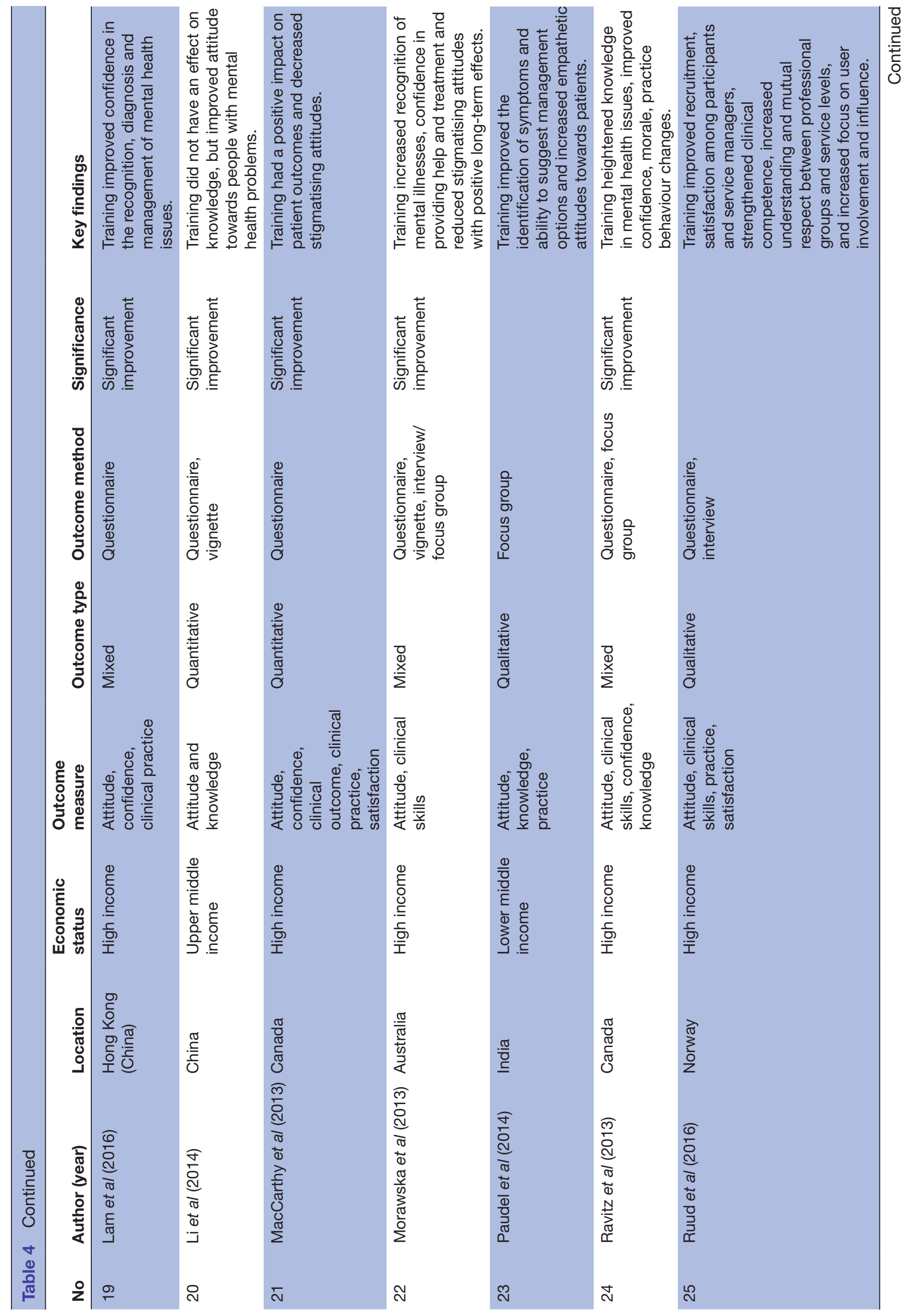




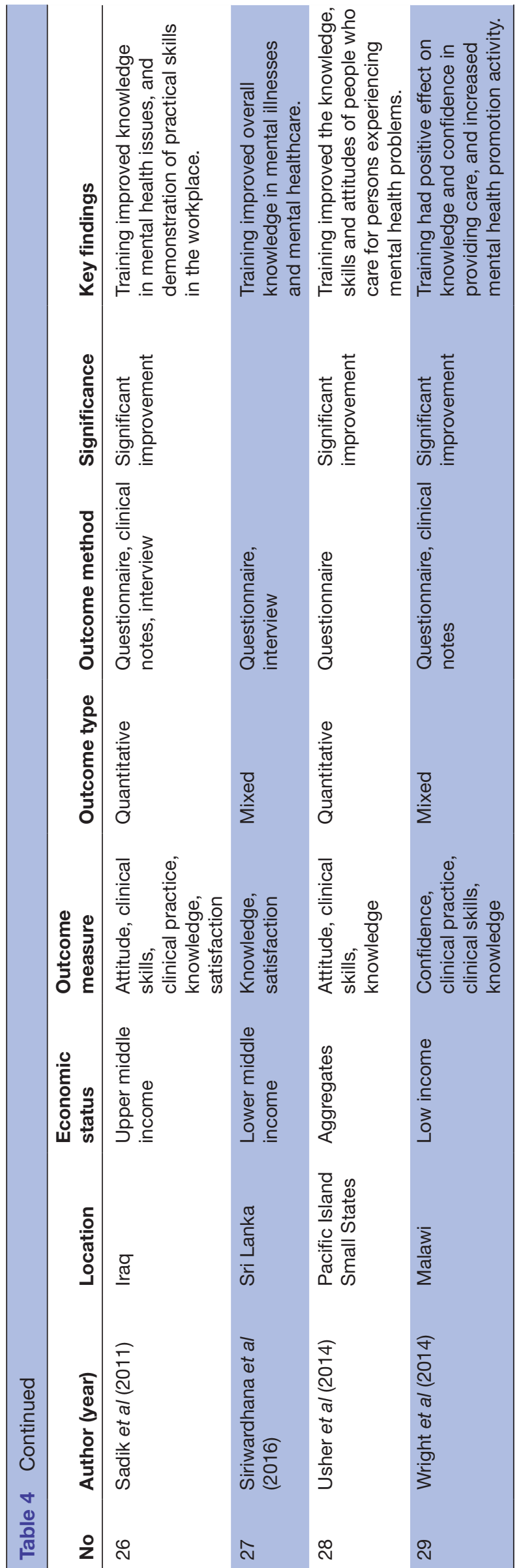

improvement in confidence and two an absolute improvement from baseline. Clinical outcome was assessed by six courses $(21 \%)$ which all showed positive outcomes. Finally, nine courses $(31 \%)$ assessed trainees' satisfaction with the course. All received positive feedback from trainees, except the use of video-conferencing to facilitate remote learning. Trainees often offered helpful suggestions for improvement for future courses.

\section{WHO policy uptake and direction of future research}

A total of six studies (21\%) referenced the WHO Mental Health Gap Action Plan (WHO, 2008) as their guiding principle, and five of these specifically used the mhGAP Intervention Guide to design training modules. A further nine studies $(31 \%)$ used other works of the WHO in their studies; in particular, the WHO Disability Assessment Schedule version $2.0^{23}$ to assess the outcomes of training, and the WHO Primary Care Guidelines for Mental Health. ${ }^{24}$ One study (3\%) was funded by WHO Department of Mental Health and Substance Abuse.

Four studies (14\%) detailed plans for ongoing training and two studies (7\%) were run as pilot studies for a future more comprehensive version of the training course. Most studies suggested themes for future research, including the need for larger and more diverse training samples, more objective outcomes and more robust evidence in the form of randomised trials.

\section{DISCUSSION}

Short mental health training for generalised health workers improves knowledge, attitude, skill and confidence, leading to improved clinical practice and better patient outcome. Crucially, such courses are cost-effective in low-resource settings and well-accepted by trainees.

Based on our search criteria, 29 studies evaluated relevant training courses since 2008 across 16 countries globally, and across a range of economic status categories. Over a third of courses (34\%) were run in three high-income countries: UK, Canada and Australia. Courses may be easier to run in high-income settings, especially considering the associated costs, and the fact that low-income settings may lack a comprehensive primary care system to allow integration of mental healthcare. Despite this, eight low-income or lower-middle-income countries set up 13 training courses; hence, perhaps a more important factor is the commitment of mental health researchers and stakeholders within these countries which is supported by the fact that half of the countries involved set up more than one training course since 2008. Another factor may be international collaborations where high-income partners help deliver training in low-income and middle-income settings. It is also important to note that this review only included studies which provided an evaluation of training; other 'unevaluated' courses may have contributed to a broader 'global' uptake. Evaluations done well are costly and time-consuming so it may be that funds have been focused on training at the cost of evaluation. 
Training courses varied enormously in size and trainee demographics, and included practice receptionists, police officers, disaster relief staff, educators and farm inspection officers. This is in line with WHO strategy to integrate mental healthcare into the community. Notably, new categories were required in our review for trainees who did not fit the current WHO classification of healthcare workers. This suggests that the classification may need updating to reflect the role of individuals without formal healthcare training who have unique access to remote or difficult-to-reach communities.

WHO did not define a suggested length for short mental health training courses, leading to varied interpretations, ranging from 1 day to 2 years. Training methods also varied. This flexibility is important for optimising each course to its particular cultural setting and available resources, and follows WHO's exemplary 'best practice' vignettes encouraging context-specific integration of mental health into primary care. Qualitative feedback from trainees suggest that culturally specific interventions, and flexibility of training, are key to course acceptability. These 'culturally and context specific' lessons are very useful for the design of future courses, as they often throw up idiosyncratic improvements for different situations, such as the success of yoga in India, ${ }^{25}$ seed planting in Uganda ${ }^{26}$ or the Friendship Bench in Zimbabwe.

This systematic review found that data collection in the field was markedly inconsistent, a problem also noted by Liu et al. ${ }^{15}$ Method, timing and outcomes for evaluation varied enormously, making it difficult to compare data across studies and draw out bigger trends, though this is perhaps a consequence of ensuring that courses remain 'culturally and context specific'. It is encouraging to see many courses measuring change in attitude among healthcare workers as stigma remains a key problem in access to good mental healthcare globally. However, it is not clear if an improvement in many of the outcomes measured (trainee knowledge, attitude, confidence, etc) actually correlates with an improved outcome for patients, and a disappointing number of studies focused on outcomes for patients. This may be due to logistical and ethical difficulties, or possibly ongoing stigma. It represents a key area for future research.

Interestingly, though this review was designed to evaluate progress since 2008 when WHO policy recommended the integration of mental healthcare into primary care, only 16 studies identified works by the WHO as design aids for the training courses and only six used mhGAP specifically. This may reflect an increased need for promotion of global policy change and the tools available, or a tendency by individual countries to base new schemes on past government-led initiatives. Nevertheless, progress in the field is promising. All 29 courses found at least some degree of improvement in outcome after training, suggesting that training non-specialist health workers is a cost-effective strategy in increasing global capacity for mental healthcare, and a field of increasing interest, with over half the studies taking place from 2014 to 2017. The recognition of mental health within global health and development priorities is also reflected by its incorporation into the United Nations Sustainable Development Agenda for 2030, and the launch of the WHO/ World Bank 2016 event 'Out of the Shadows: Making Mental Health a Global Priority'.

\section{Limitations}

This study has some limitations. First, it did not include studies which evaluated training for medical specialists (ie, non-general practitioners) or students, or training targeting specific subpopulations (eg, refugees), or single conditions (eg, depression only). Second, publications on training without evaluation were not included; hence, there may be several more (effective) mental health training courses for non-specialist health workers globally. Third, on occasion it proved difficult to categorise outcomes according to the schema mentioned above; for instance, it is difficult to know whether to classify the ability to identify mental health disorders in vignettes as skill or knowledge. We consistently categorised this as skill, in line with the definition of skill used by Kirkpatrick $^{20}$ as 'the ability to perform a task well, usually gained by training or experience'. We are aware that the interpretation of other researchers on this point may vary. Unfortunately, due to lack of resources and researcher unavailability, we were unable to re-run our search after 31 May 2017; more studies may well have been published since the end date of our search which are not included in this review.

\section{CONCLUSIONS}

Training non-specialist health workers is an effective strategy to increase global capacity for mental healthcare, improving knowledge, attitude, skill and confidence, as well as clinical practice and patient outcome. Existing studies provide examples of many training and evaluation methods, but evidence to draw conclusions on the efficacy of different training techniques is insufficient. Areas for future focus include developing standardised evaluation methods and outcomes to allow cross-comparison between studies, and optimisation of course structure.

Acknowledgements The authors would like to thank Isla Kuhn (Librarian, School of Clinical Medicine) for her generous support and guidance with the literature search. In addition, we would like to extend our gratitude to Daniel Fountain, Teresa Krieger and Jennifer Stuart (University of Cambridge) for their initial involvement discussing potential research questions in global mental health.

Contributors AC: literature search, figures, study design, data collection, data analysis, data interpretation, writing, critical revision. DV: literature search, figures, study design, data collection, data analysis, data interpretation, writing, critical revision, referencing. GL: data analysis and data interpretation (methodological quality of studies only). TVB: literature search, data collection, data analysis, data interpretation, writing, critical revision.

Funding The authors have not declared a specific grant for this research from any funding agency in the public, commercial or not-for-profit sectors.

Competing interests None declared.

Patient consent Not required. 
Provenance and peer review Not commissioned; externally peer reviewed.

Data sharing statement № additional data available.

Open access This is an open access article distributed in accordance with the Creative Commons Attribution Non Commercial (CC BY-NC 4.0) license, which permits others to distribute, remix, adapt, build upon this work non-commercially, and license their derivative works on different terms, provided the original work is properly cited, appropriate credit is given, any changes made indicated, and the use is non-commercial. See: http://creativecommons.org/licenses/by-nc/4.0/.

\section{REFERENCES}

1. Murray CJ, Vos T, Lozano R, et al. Disability-adjusted life years (DALYs) for 291 diseases and injuries in 21 regions, 1990-2010: a systematic analysis for the Global Burden of Disease Study 2010. Lancet 2012;380:2197-223.

2. World Health Assembly. Global burden of mental disorders and the need for a comprehensive, coordinated response from health and social sectors at the country level: report by the Secretariat. Geneva: World Health Assembly, 2012.

3. Vigo D, Thornicroft G, Atun R. Estimating the true global burden of mental illness. Lancet Psychiatry 2016;3:171-8.

4. Steel Z, Marnane C, Iranpour C, et al. The global prevalence of common mental disorders: a systematic review and meta-analysis 1980-2013. Int J Epidemiol 2014;43:476-93.

5. World Health Organization. Mental health action plan 2013-2020. Geneva: World Health Organization, 2013.

6. Bloom DE, Cafiero ET, Jané-Llopis E, et al. The global economic burden of non-communicable diseases. Geneva, 2011.

7. Lasalvia A, Zoppei S, Van Bortel T, et al. Global pattern of experienced and anticipated discrimination reported by people with major depressive disorder: a cross-sectional survey. Lancet 2013;381:55-62.

8. Thornicroft G, Brohan E, Rose D, et al. Global pattern of experienced and anticipated discrimination against people with schizophrenia: a cross-sectional survey. Lancet 2009;373:408-15.

9. Prince M, Patel V, Saxena S, et al. No health without mental health. Lancet 2007;370:859-77.

10. Patel V, Boyce N, Collins PY, et al. A renewed agenda for global mental health. Lancet 2011;378:1441-2.

11. World Health Organization, World Organisation of National Colleges Academies and Academic Associations of General Practitioners/ Family Physicians. Integrating mental health into primary care: a global perspective. Geneva, Switzerland London: World Health Organization; Wonca, 2008.

12. World Health Organization. mhGAP: Mental health gap action programme: scaling up care for mental, neurological and substance use disorders. Geneva: World Health Organization, 2008.

13. Moher D, Liberati A, Tetzlaff J, et al. Preferred reporting items for systematic reviews and meta-analyses: the PRISMA statement. Ann Intern Med 2009;151:264-9.

14. Schardt C, Adams MB, Owens T, et al. Utilization of the PICO framework to improve searching PubMed for clinical questions. BMC Med Inform Decis Mak 2007;7:16.

15. Liu G, Jack H, Piette A, et al. Mental health training for health workers in Africa: a systematic review. Lancet Psychiatry 2016;3:65-76.

16. Wells GAS, O'Connell D, Peterson J, et al. The Newcastle-Ottawa Scale (NOS) for assessing the quality of nonrandomised studies in meta-analyses. 2000.

17. Goldet G, Howick J. Understanding GRADE: an introduction. J Evid Based Med 2013;6:50-4.

18. Slim K, Nini E, Forestier D, et al. Methodological index for nonrandomized studies (minors): development and validation of a new instrument. ANZ J Surg 2003;73:712-6.

19. World Health Organisation. Classifying health workers: mapping occupations to the international standard classification. Geneva: World Health Organisation, 2008.

20. Kirkpatrick DL. Evaluation of training. Training and development handbook. New York: McGraw Hill, 1967:87-112.

21. Hutchinson L. Evaluating and researching the effectiveness of educational interventions. BMJ 1999;318:1267-9.

22. Wojtczak A. Glossary of medical education terms: Part 1. Med Teach 2002;24:216-9.

23. Üstün TB. Measuring health and disability: manual for WHO Disability Assessment Schedule WHODAS 2.0. Geneva: World Health Organization, 2010.

24. Jenkins R. Royal Society of Medicine (Great Britain), WHO Collaborating Centre for Research and Training in Mental Health. WHO guide to mental and neurological health in primary care: a guide to mental and neurological ill health in adults, adolescents, and children, UK ed. London: Royal Society of Medicine, 2004.

25. Chatterjee S, Chowdhary N, Pednekar S, et al. Integrating evidencebased treatments for common mental disorders in routine primary care: feasibility and acceptability of the MANAS intervention in Goa, India. World Psychiatry 2008;7:39-46.

26. Petersen I, Ssebunnya J, Bhana A, et al. Lessons from case studies of integrating mental health into primary health care in South Africa and Uganda. Int J Ment Health Syst 2011;5:8. 